\author{
CAPÍTULO 41 \\ A PRÁTICA PROFISSIONAL DO PSICÓLOGO ESCOLAR FRENTE AS \\ DEMANDAS DA $5^{a}$ COORDENADORIA REGIONAL DE DESENVOLVIMENTO DA \\ EDUCAÇ̃̃O
}

\begin{abstract}
Jefferson da Silva Rodrigues ${ }^{1}$, André Sousa Rocha ${ }^{2}$, Luiz Wescley Fontenele Moura ${ }^{3,}$ Antonia Mávilla Sales da Cunha $^{4}$, Juliana Maria da Silva Trajano ${ }^{5}$ ${ }^{1}$ Faculdade Ieducare FIED-UNINTA, (jeffersonrdo2000@gmail.com) 2 Universidade São Francisco, (asroccha@hotmail.com) ${ }^{3}$ Faculdade Ieducare FIED-UNINTA, (wescleyfm18@gmail.com)

${ }^{4}$ Faculdade Ieducare FIED-UNINTA, (mavillascunha@gmail.com)

${ }^{5}$ Faculdade Ieducare FIED-UNINTA, (julianatrajanopsi@gmail.com)
\end{abstract}

\title{
Resumo
}

Objetivo: compreender como se desenvolve a atuação prática de um psicólogo na área Educacional e Escolar, bem como depreender as competências e habilidades utilizadas por esse profissional. Método: Trata-se de um estudo de delineamento básico, qualitativo e descritivo de natureza relato de experiência desenvolvido durante o Estágio Básico I do curso de Psicologia da Faculdade Ieducare - FIED, em que, a vivência em tese foi realizada na $5^{\text {a }}$ Coordenadoria Regional de Desenvolvimento da Educação - CREDE 5, que tem sede física na cidade de Tianguá-CE. Resultados: Diante o exposto, a CREDE, é um órgão de execução, articulação e desenvolvimento da educação, regionalmente/local, vinculada à Secretaria Estadual de Educação, que abrange nove cidades Carnaubal, Croatá, Guaraciaba do Norte, Ibiapina, Ipu, São Benedito, Tianguá, Ubajara e Viçosa do Ceará. A priori, depreender as nuances do trabalho do psicólogo escolar é um trabalho que gera angústias e frustrações, visto as dificuldades percebidas para uma prática exequível do saber psicológico e entender que muitas vezes a solução dos problemas inerentes a prática foge da responsabilidade e das atribuições e responsabilidades do psicólogo. Considerações Finais: Logo, o Estágio Básico I foi fundamental para compreender os processos educacionais bem como se desenvolve a prática do psicólogo nas demandas e como lidar com as questões organizacionais que se apresentam na rotina do psicólogo escolar.

Palavras-chave: Estágio Básico; Formação profissional; Psicologia Escolar e Educacional.

Área Temática: Temas transversais - Outros.

E-mail do autor principal: jeffersonrdo2000@gmail.com Inovações 


\title{
1 INTRODUÇÃO
}

APsicologia enquanto ciência e profissão, o que permeia as nuances práticas e teóricas, não deve ser percebida como uma ciência que se restringe ao modelo médico clínico, em que otem se um atendimento centrado no indivíduo, bem como não se centra as explicações da constituição do ser humano nas características intrapsíquicas (TANAMACHI, 2002). Assim, é preciso que se constitua uma Psicologia que estude, pesquise e atue integralmente, estruturada em um trabalho social, em equipes multiprofissionais e utilizem diversas maneiras para responder os entraves da realidade social vivenciada por indivíduos com características históricas e culturais (SOUZA; FACCI; SILVA, 2018).

Visto isso, observa-se que a ciência psicológica, em seu caráter prático e profissional, permite que os psicólogos atuem em diversas áreas. Sendo assim, a Psicologia Escolar e Educacional é uma das áreas de pesquisa que se fazem eminentes no que se entende como a construção da Psicologia como ciência e profissão no país (SOUZA, 2009). Logo, entender melhor o que se caracteriza como sendo a Psicologia Educacional e Escolar é uma tarefa necessária. Contudo, há muitos embates, no âmbito discursivo, daquilo que a identifica e conceitua-a, por conta de divergências teóricas. Isto posto,

\begin{abstract}
compreendendo esta como uma área de atuação profissional que toma a escola e as relações que ali se estabelecem como foco de ação, visando facilitar o processo ensino-aprendizagem - que não acontece sem que se considere a relação professoraluno, o conteúdo e o contexto (incluindo aqui interesses e necessidades doalunado) e o desenvolvimento singular do sujeito, em simultâneo, proporcionandosua inserção. (CHAVES; SILVA; CALVACANTE, 2018, p.644)
\end{abstract}

Dessa forma, para se poder estar oferecendo bons serviços e para que se efetive de forma satisfatória aquilo que se propõe, a Psicologia Escolar e Educacional ao longo dos anos tem debatido e instigado "inúmeras reflexões acerca da formação e da prática dos profissionais que nela atuam; sobretudo, a necessidade de redefinição do papel do psicólogo na escola e de reestruturação de sua formação acadêmica, com dezenas de trabalhos publicados." (SOUZA, FACCI; SILVA, 2018).

Com isso, se faz importante conhecer as práticas da Psicologia Escolar. Além de ser ummeio de visibilizar esse campo de atuação da Psicologia e contribuir com o debate sobre as possibilidades e desafios nas intervenções do psicólogo escolar, um dos meios para isso ocorrer é a experiência no transcurso da formação acadêmica através dos estágios, que:

Configurando-se como integrantes essenciais da formação profissional, os estágios compõem a grade curricular de Psicologia e são um dos momentos mais aguardados pelos discentes. Trata-se de uma atividade obrigatória que integra o currículo do curso de graduação em Psicologia e propõe ao estudante um contato inicial com o exercício da profissão, diminuindo a distância entre o campo de atuação do psicólogo e a sala

\section{E - book Pesquisa e Tecnologia: Protagonismo e Inovações}


de aula. (SANTOS; NOBREGA, 2017, p.2)

No que lhe concerne, a finalidade desse estudo se configura ao relato de experiência, referente à disciplina de Estágio Básico I do curso de Psicologia da Faculdade Ieducare FIED, em que, a vivência em tese foi realizada na $5^{a}$ Coordenadoria Regional de Desenvolvimento da Educação - CREDE 5, que tem sede física na cidade de Tianguá, na região Norte do Ceará. Diante o exposto, a CREDE, é um órgão de execução, articulação e desenvolvimento da educação, regionalmente/local, vinculada à Secretaria Estadual de Educação, que abrange nove cidades, sendo elas: Carnaubal, Croatá, Guaraciaba do Norte, Ibiapina, Ipu, São Benedito, Tianguá, Ubajara e Viçosa do Ceará.

Ainstituição regional, da mesma forma como a Secretaria Estadual de Educação, possui suas subdivisões hierárquicas organizacionais, denominadas Células. Porém, mediante aos objetivos desse trabalho, condiz aqui falar em específico da Célula de Desenvolvimento da Escola e da Aprendizagem (CEDEA), e ainda no que diz respeito as ações desenvolvidas no Núcleo de Formação Pedagógica, pelo profissional de Psicologia em conjuntocom os demais constituintes do Núcleo.

Desse modo, o objetivo do estudo foi compreender como se desenvolve a atuação prática de um psicólogo na área Educacional e Escolar, bem como depreender as competências e habilidades utilizadas por esse profissional.

\section{MÉTODO}

A presente pesquisa é constituída por um estudo de delineamento básico, qualitativo e descritivo de natureza relato de experiência desenvolvido durante o Estágio Básico I que constituí a matriz curricular de uma Instituição de Ensino Superior Privada, localizada no Norte do Ceará. A presente disciplina, segue as Diretrizes Curriculares Nacionais (DCNs) para os cursos de graduaçãoem Psicologia propostas na Resolução No 5, de 15 de Março de 2011 do Conselho Federal de Psicologia (CFP). Isso posto, pode-se citar que no artigo $5 .^{\circ}$ nos incisos, V e VI, da mesma resolução ele preconiza:

Art.5. - A formação em Psicologia exige que a proposta do curso articule os conhecimentos, habilidades e competências em torno dos seguintes eixos estruturantes:

$\mathrm{V}$ - Interfaces com campos afins do conhecimento para demarcar a natureza e a especificidade do fenômeno psicológico e percebê-lo em sua interação com fenômenos biológicos, humanos e sociais, assegurando uma compreensão integral e contextualizada dos fenômenos e processos psicológicos;

\section{E - book Pesquisa e Tecnologia: Protagonismo e Inovações}


VI - Práticas profissionais voltadas para assegurar um núcleo básico de competênciasque permitam a atuação profissional e a inserção do graduado em diferentes contextosinstitucionais e sociais, de forma articulada com profissionais de áreas afins. (MEC, 2011).

Dessa forma, a experiência vivenciada é uma das maneiras e medidas de exigência para formação acadêmica do futuro profissional. Diante disso, esse estágio se caracterizou em uma carga horária total de 40h, dividida em $20 \mathrm{~h}$ prática e $20 \mathrm{~h}$ de supervisão. A instituição cedente, foi a $5^{\text {a }}$ Coordenadoria Regional de Desenvolvimento da Educação do município de Tianguá-CE, que recebeu 10 estagiários no total, dos quais sete eram da disciplina Estágio Básico II, com carga horária diferente. De modo logístico, os estagiários se organizaram em duplas conforme a disponibilidade do profissional. Sendo assim, foram distribuídos em cinco turnos correspondentes as $20 \mathrm{~h}$ semanais de trabalho da psicóloga. Portanto, foram divididas às $20 \mathrm{~h}$ de práticas em cinco encontros, um por semana, com duração de quatro horas cada.

O estágio, ainda possui caráter observacional, em que o principal instrumento era a observação, que possui uma finalidade conhecida de antemão, descrita por meio dos objetivos. Assim, os dados coletados a partir da observação fornecem subsídios para diagnosticar uma situação problema, facilitar a escolha das técnicas e procedimentos empregados na pesquisa e na avaliação da sua eficácia (DANNA; MATOS, 2006).

Por isso, quando em campo de estágio, os estagiários limitavam-se ao olhar e escuta atenta das ações específicasdo psicólogo, sem deixar de considerar o ambiente e questões que entornam e implicam diretamente no trabalho do profissional. Mas também, embora não houvesse intervenção tal qual a de competência do psicólogo, quando solicitado, envolvia-se sugestivamente e pontual, quanto as ações a serem executadas.

\section{RESULTADOS E DISCUSSÃO}

\section{Relato de Experiência}

O trabalho do psicólogo, seja qual o contexto em que o profissional esteja inserido, encontram-se dificuldades. Nesse sentido, “o psicólogo escolar ainda encontra dificuldades para legitimar seu espaço de trabalho como membro das equipes técnicas presentes nas escolas públicas em todo território brasileiro" (GUZZO; MEZZALIRA, 2011, p.13).

Por isso, quando se teve o primeiro contato com a instituição cedente e com o

\section{E - book Pesquisa e Tecnologia: Protagonismo e Inovações}


profissional de Psicologia, essa foi uma das características que foram pertinentes no discurso, visto que, mesmo o trabalho do psicólogo educacional e escolar seja datada assim como a própria profissão do psicólogo no Brasil (GUZZO, 2001) percebeu-se que os profissionais da Educação assim como os familiares e por vezes os alunos, não compreendem ou desconhecem a práxis psicológica nessa área (CASSINS et al., 2007; GASPAR; COSTA, 2011).

Diante disso, torna-se um desafio e um compromisso ético do psicólogo, o papel de agente formador nesse contexto, o que condiz com os princípios fundamentais $\mathrm{V}$ e VI, instituídos no Código de Ética do Profissional Psicólogo (CEP), descritos na Resolução nº 10 de 2005 pelo Conselho Federal de Psicologia (2005):

V. O psicólogo contribuirá para promover a universalização do acesso da populaçãoàs informações, ao conhecimento da ciência psicológica, aos serviços e aos padrões éticos da profissão.

VI. O psicólogo zelará para que o exercício profissional seja efetuado com dignidade,rejeitando situações em que a Psicologia esteja sendo aviltada.

Por conseguinte, depreendeu-se que há um constante zelo pela profissão nas ações do psicólogo educacional da CREDE 5, em que o profissional repetira por diversas vezes, direcionando a palavra aos estagiários, a importância de seguir o que preconiza o Código de Ética, em tudo que se faz, inclusive, no que poderia ser compartilhado com os estudantes, além de enfatizar as relações de poder e a importância de respeitar as hierarquias. Dessa forma, foram apresentadas aos estagiários como se desenvolviam as atividades do Núcleo de FormaçãoPedagógica, em específico, o trabalho do psicólogo, que atua na rede estadual. Assim, depreendeu-se que o psicólogo tinha atribuições de:

Desenvolvimento de trabalhos com educadores e alunos, visando a explicitação e superação de entraves institucionais ao funcionamento produtivo das equipes e ao crescimento individual de seus integrantes.

Desenvolver, junto aos membros da comunidade escolar (alunos, professores, núcleo gestor), atividades visando prevenir, identificar e resolver problemas psicossociais que possam bloquear, na escola, o desenvolvimento de potencialidades, autorrealização e o exercício da cidadania consciente.

Desenvolver projetos de orientação profissional, visando um melhor aproveitamento e desenvolvimento do potencial humano, fundamentados no conhecimento psicológico e numa visão crítica do trabalho e das relações de mercado de trabalho.

Diagnosticar as dificuldades dos alunos e encaminhar aos serviços de atendimento da comunidade, aqueles que requeiram diagnóstico e tratamento de problemas psicológicos específicos, cuja natureza transcenda a possibilidade de solução no âmbito da escola. Supervisionar, orientar e executar trabalhos na área da Psicologia Educacional. (CENTEC, 2019)

Logo, as atividades a serem executadas foram inúmeras, assim como o público Inovações 
correspondeste a essas atividades. Além disso, outro ponto eminente diz respeito a incapacidade humana de atender as demandas de todo o território demandado da CREDE 5, pois são nove cidades com somatória de mais 30 escolas estaduais e mais de 14 mil indivíduos para desenvolver seu trabalho, incluindo alunos, professores e gestores. Por conta disso, percebeusea frustração do profissional perante a essa realidade.

Durante o decorrer dos encontros, foram apresentadas também os documentos utilizados na prática, que em sua maioria, são relatórios de uso individual a multiprofissional. A Resolução CFP 06/2019 frisa muito bem as Orientações Sobre Elaboração de Documentos Escritos Produzidos pela (o) Psicóloga (o) no Exercício Profissional:

Art. 11 O relatório psicológico consiste em um documento que, por uma exposição escrita, descritiva e circunstanciada, considera os condicionantes históricose sociais da pessoa, grupo ou instituição atendida, podendo também ter caráter informativo. Visa a comunicar a atuação profissional da (o) psicóloga(o) em diferentes processos de trabalho já desenvolvidos ou em desenvolvimento, podendo gerar orientações, recomendações, encaminhamentos e intervenções pertinentes à situação descrita no documento, não tendo como finalidade produzir diagnóstico psicológico. (CFP, 2019).

Um dos relatórios, servia de comprovação dos trabalhos exercidos pelo psicólogo durante o referido mês, em que é encaminhado para os responsáveis da Secretaria Estadual de Educação, os outros se referiam as visitas e as formações desenvolvidas com gestores e professores. Ainda no período delimitado, o profissional permitiu, sugestivamente, a participação dos estagiários na elaboração de uma atividade de intervenção em uma escola da rede estadualde ensino, bem como a colaboração dos outros técnicos do Núcleo de Formação Pedagógica, pois,

O psicólogo não deve ser aquele que traz um saber ou uma resposta pronta; ele interagecom os demais atores para construir uma solução viável no contexto da Educação, tanto na escola quanto na universidade ou em uma organização não governamental. Nesse processo, é importante que o psicólogo construa uma postura crítica e criativa e esteja aberto aos múltiplos desafios e possibilidades presentes nos contextos educacionais (DIAS; PATIAS; ABAID, 2014, p.110).

O Problema em questão, deu-se a partir de uma demanda específica de uma turma da escola X, assim como em outras demandas de atribuição do psicólogo educacional e escolar. Ele recebe, geralmente, dos gestores escolares, analisa a questão, busca entender o contexto em que se insere tal demanda, compreendendo busca ações condizentes com suas capacidades técnicas, teóricas e práticas, o que denota novamente o que se pede o Código de Ética:

Art. 1. $^{\mathbf{o}}-$ São deveres fundamentais dos psicólogos:

b) Assumir responsabilidades profissionais somente por atividades para as quais estejacapacitado pessoal, teórica e tecnicamente; Inovações 
c) Prestar serviços psicológicos de qualidade, em condições de trabalho dignas e apropriadas à natureza desses serviços, utilizando princípios, conhecimentos e técnicas reconhecidamente fundamentados na ciência psicológica, na ética e na legislação profissional; (CFP, 2005).

Por fim, estrutura a ação para sua efetivação prática referente ao problema demando. A partir disso, foi desenvolvido para o problema da escola $\mathrm{X}$, em que a turma fora caracterizada como desanimada, com perfil caracterizado como baixo desempenho, triste, ansiosa, que não conseguia se entender direito, tanto em relações a conflitos como ao autoconhecimento, a atividade Teatro Social, baseado na teoria das Máscaras de Carl Jung, em que seria esclarecido a importância do Autoconhecimentopara poder lidar com os problemas que nos envolvem. Dessa forma, a atividade se daria a partir da construção de uma máscara por aluno, em que cada um escreveria três qualidades, algo positivo que lhe representara e três características que ele escondia, algo que considera ruim, para se poderevocar para a consciência a importância de se conhecer e assim o profissional entender melhor a situação da turma e articular possíveis soluções.

Por sua vez, quando foi efetivada a ação com os alunos, a psicóloga já havia visitada anteriormente a escola conversado com os pais e alunos. Porém, visto a necessidade de um espaço para se falar abertamente sem a presença de uma autoridade de controle presente, sentiu-se a necessidade desse momento específico. Logo, a psicóloga tentou adequar seu comportamento,gestos e fala para que o público alvo, no caso os alunos, pudessem se sentir mais a vontade e dispostos a falar, ou seja, o principal instrumento utilizado, geralmente foi a fala, e

Todo ser humano precisa ter o seu momento para falar, colocar suas ideias, expressar suas opiniões e sentimentos. Na escola, geralmente, esse espaço ou é limitado,ou não existe. Percebe-se então, que a presença do psicólogo nas instituições de ensinoé de extrema valia e importância para esse contexto. Em meio às diversas habilidadesque este profissional deve apresentar, inclui-se, proporcionar aos alunos um momentoem que eles possam se expressar como seres que além de possuir suas capacidades cognitivas, têm valores, emoções e opiniões próprias que não podem ser silenciadas, mas sim compartilhadas (ELIAS; VERAS, 2008, p.183).

Assim, depois que se possibilita esse processo de fala ativa do aluno e escuta qualificada do profissional, pode-se entender melhor a origem dos comportamentos demandados. Por fim, buscou-se conscientizar a importância de mudança de comportamento, de respeito mútuo e principalmente a ter resiliência, que faz parte do trabalho de Habilidades Sócio emocionais, conduzidos pelos professores da rede estadual e resiliência é frequentemente referida por processos que explicam a superação de crises e adversidades em indivíduos, grupos e

\section{E - book Pesquisa e Tecnologia: Protagonismo e Inovações}


organizações (YUNES; SZYMANSKI, 2001).

Em seguida, foi lido um poema que instigava e motivava os alunos para mudar e aproveitar melhor a vida. Posterior a atividade, surgiu um problema de um aluno em específico, e que o profissional conduziu individualmente e sigilosa. Após terminado, passaram-se as impressões a direção da escola para futuras mediações de problemas e sugestões de como enfrentar os problemas.

\section{Análise da Experiência}

A priori, depreender as nuances do trabalho do psicólogo escolar é um trabalho que gera angústias e frustrações, visto as dificuldades percebidas para uma prática exequível do saber psicológico e entender que muitas vezes a solução dos problemas inerentes a prática foge da responsabilidade e das atribuições e responsabilidades do psicólogo.

Da mesma forma, percebeu-se o quanto o profissional psicólogo da CREDE 5, zela pelos princípios éticos em suas ações e age de forma plausível frentes suas dificuldades e demandas. Assim, de maneira sucinta, depreende o quanto precisa-se está qualificado para qualquer que seja as situações, e ter o discernimento daquilo que não compete as suas capacidades, bem como a importância do sigilo profissional.

Em suma, o momento do estágio, possibilitou a compreensão de que os problemas e demandas não possui técnicas ou métodos prontos e tem-se a necessidade de pedir ajuda, bem como entender os inúmeros contextos e variáveis que envolvem a práxis no âmbito da escola, visto que se deve considerar.

Por fim, a experiência de se observar e poder reflexionar a atuação de um profissional é de suma importância para formação acadêmica e de futuro profissional, bem como a construçãode relações e afetos permitem também o desenvolvimento pessoal do estagiário.

\section{CONSIDERAÇÕES FINAIS}

Diante da experiência vivenciada, conclui-se que a presença do psicólogo escolar nesse equipamento é de suma importância. Porém, ainda é envolta de dificuldades com origens, em especial, na falta de conhecimento dos professores, gestores, alunos e familiares, no que condiz a prática profissional para enfrentamento dos problemas seja relacionas aprendizagem, sofrimento psíquico e outros. Logo, o Estágio Básico I foi fundamental para compreender os processos educacionais bem como se desenvolve a prática do psicólogo nas demandas e como

\section{E - book Pesquisa e Tecnologia: Protagonismo e Inovações}


lidar com as questões organizacionais presentes na rotina do psicólogo escolar.

\section{REFERÊNCIAS}

ANTUNES, M. A. M. Psicologia Escolar e Educacional: história, compromissos e perspectivas. Revista Semestral da Associação Brasileira de Psicologia Escolar e Educacional (ABRAPEE), v. 12, n. 2, p. 469 - 475, 2008.

CASSINS, A. M. Manual de psicologia escolar/educacional. Curitiba, 2007.

CENTEC- INSTITUTO CENTRO DE ENSINO TECNOLÓGICO. Edital 011/2019. Processo Seletivo Para Analista - Psicólogo, Fortaleza, p. 1 - 20, 2019.

CHAVES, J. R.; SILVA, P. F. da; CALVACANTE, A. C. S. "Na essência somos iguais, na diferença nos respeitamos": Estágio em Psicologia Escolar. Psicologia Escolar e Educacional.Psicologia Escolar e Educacional, v. 22, n. 3, p. 643 - 645, set-dez 2018. ISSN 2175-3539. Disponível em: https://doi.org/10.1590/2175-35392018035060. Acesso em: 06/12/2019.

CONSELHO FEDERAL DE PSICOLOGIA. RESOLUÇÃO n. ${ }^{\circ}$ 6, DE 29 DE MARÇO DE 2019. 2019. Disponível em: https://site.cfp.org.br/wp-content/uploads/2019/09/Resolu\%C3\% A7\%C3\%A3o-CFP-n-06-2019-comentada.pdf. Acesso em: $06 \mathrm{dez} 2019$.

CONSELHO FEDERAL DE PSICOLOGIA. Código de ética profissional do Psicólogo. Resolução CFP 010/2005, Brasília, p. 1 - 20, 27/08/2005. Disponível em: http://www. pol.org.br/pol/export/sites/default/pol/legislacao/legislacaoDocumentos/codigo_etica.pdf\&g t.Acesso em: $06 \mathrm{dez} 2019$.

DANNA, M. F.; MATOS, M. A. Aprendendo a Observar. São Paulo: Edicon, 2006.

DIAS, A. C. G.; PATIAS, N. D.; ABAID, J. L. W. Psicologia Escolar e possibilidadesna atuação do psicólogo: algumas reflexões. Psicologia Escolar e Educacional, Maringá, v. 18, n. 1, p. 105 - 111, Maio 2014. ISSN 2175-3539. Disponível em: https://doi.org/10.1590/S1413-85572014000100011. Acesso em: 06 dez 2019.

ELIAS, G. G. P.; VERAS, M. O. Psicologia escolar: abrindo espaço para a fala, a escuta e o desenvolvimento interpessoal. Revista abordagem gestalt, Goiânia, v. 14, n. 2, p. 182 189, dez 2008. Disponível em: http://pepsic.bvsalud.org/scielo.php?script=sci_arttext\&pid= S1809-68672008000200005\&lng=pt\&nrm=iso. Acesso em: $04 \mathrm{dez} 2019$.

GASPAR, F. D. R.; COSTA, T. A. Afetividade e atuação do psicólogo escolar. Psicologia Escolar e Educacional, v. 15, n. 1, p. 121 - 129, Jul 2011. ISSN 2175-3539. Disponível em: https://doi.org/10.1590/S1413-85572011000100013. Acesso em: 04 dez 2019.

GUZZO, R. S. L. Formando Psicólogos Escolares no Brasil: Dificuldades e Perfectivas. In: WECHSLER, S. M. (org.). Psicologia escolar: pesquisa, formação e prática. Campinas: Alínea, 2001. p. 75 - 92. Inovações 
GUZZO, R. S. L.; MEZZALIRA, A. S. da C. 2008 - Ano da educação para os psicólogos - encaminhamentos próximos. In: MARINHO-ARAUJO, C. M.; GUZZO, R. S. L. (org.). Psicologia escolar: identificando e superando barreiras. Campinas: Alínea, 2011. p. 11 - 31. MINISTÉRIO DA EDUCAÇÃO CONSELHO NACIONAL DE EDUCAÇÃO. Resolução No 5, 15 de março de 2011. Diretrizes Curriculares Nacionais para os cursos de graduação em Psicologia, Brasília, 2011. Disponível em: http://portal.mec.gov.br/index.php?option=com_ docman \&view=download\&alias=7692-rces005-11-pdf\&category_slug=marco-2011-pdf \& Itemid=30192. Acesso em: $04 \mathrm{dez} 2019$.

SANTOS, A. C. dos; NÓBREGA, D. O. da. Dores e Delícias em ser Estagiária: o Estágio na Formação em Psicologia. Psicologia: Ciência e Profissão, v. 37, n. 2, p. 515 - 528, Jun 2017.ISSN 1982-3703. Disponível em: https://doi.org/10.1590/1982-3703002992015. Acesso em:10 dez 2019.

SOUZA, M. P. R. de. Psicologia Escolar e Educacional em busca de novas perspectivas. Psicologia Escolar e Educacional, v. 13, p. 179 - 182, 06 2009. ISSN 1413-8557.

Disponível em: http://www.scielo.br/scieloOrg/php/articleXML.php?lang=en\&pid= S1413-85572009000100021. Acesso em: 05 dez 2019.

SOUZA, M. P. R. de; FACCI, M. G. D.; SILVA, S. M. C. da. EDITORIAL 22.1 - Sobre as Diretrizes Curriculares Nacionais para os cursos de graduação em Psicologia. Psicologia Escolar e Educacional, v. 22, n. 1, p. 13 - 16, jun-mar 2018. ISSN 2175-3539.

Disponívelem: https://doi.org/10.1590/2175-3539201801001. Acesso em: 10 dez 2019. 